\title{
PERMVENCIA DE MÉTODOS DE CURACIÓN POPULARES EN UN SISTEMA DE CUIDADOS MODERNO
}

\section{Rafael Villar Dávila * , Carmen Pulido Carrascosa ** , Carmen Jiménez Díaz *, Alfonso Cruz Lendínez *, Pedro G arcía Ramiro * \\ * Enfermero/a Profesor/a Escuela de Ciencias de la Salud. U niversidad de Jaén ** Enfermera Complejo Hospitalario de Jaén}

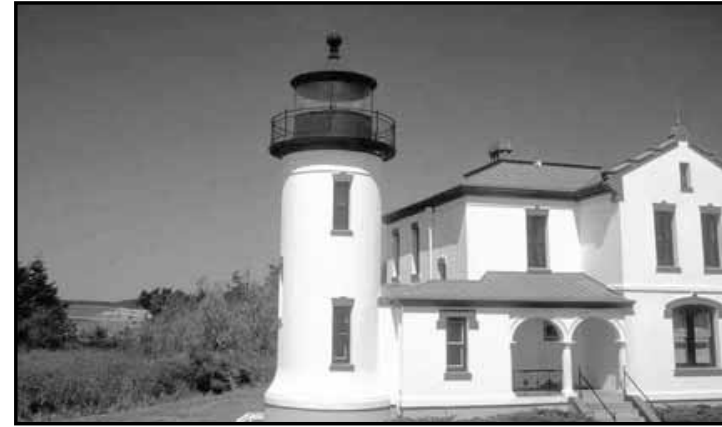

PERDURANCE OF POPULAR HEALING METHODS IN A MODERN HEALTH CARE SYSTEM

\section{SUMMARY}

Within the frame of cultural relativism and transcultural care, this work aims to globally approach the phenomenon of healers or quakers and "folk care", and understand their coexistence with highly qualified health care systems; to find out the profile, methods and rites that are used, some common features among healers and the motives and experiences of those who have sought for their help.

In order to document and complete this descriptive ethnography, a questionnaire was designed and handed out by means of an interview to seven people who have used the services of healers within the province of Jaén.

Amongst the relevant results are the thoughtful and respectful manners of the healers and their interest for the person. The healers surround themselves of a religious-mystic atmosphere and use the laying on of hands and herbs.

We can conclude that the coexistence of traditional methods with a modern health system is mutually enriching, provides differentiating elements to the patient's care and, so far, in certain circles, it does not seem bound to disappear.
KEY WORDS: Transcultural nursing, quackery, folk care.

\section{RESUMEN}

En el marco del relativismo cultural y de los cuidados transculturales, este trabajo pretende conocer globalmente el fenómeno del curanderismo y los "cuidados populares" y comprender su coexistencia con modelos de salud altamente cualificados; conocer el perfil, los métodos y ritos utilizados y las características comunes a los curanderos y los motivos y experiencias de las personas que han asistido a ellos.

Para documentar y completar esta etnografía descriptiva se ha diseñado y administrado mediante entrevista una encuesta a 7 personas que han recibido atención de curanderos en el entorno de la provincia de Jaén.

Entre los resultados tienen especial relevancia el trato cordial y respetuoso del curandero y su interés por la persona. Se rodean de un ambiente místico-religioso y utilizan la imposición de manos y el uso de hierbas.

Podemos concluir con la idea de que la coexistencia de métodos tradicionales en un sistema de salud moderno es recíprocamente enriquecedor, aportan elementos diferenciadores en la atención al paciente y por el momento, en determinados ambientes, no parece llamada a desaparecer.

PALABRAS CLAVE: Enfermería transcultural, curanderismo, cuidados populares.

\section{INTRODUCCIÓN}

La sintetización del concepto de cultura y cuidado, ampliamente relacionados, favoreció la creación de la enfermería transcultural (ETC). Las creencias, valores y estilos de vida deseados de los seres humanos han sido incorporados a la enferme- 
ría y a los servicios de salud. Más y más personas esperan de las enfermeras y de los servicios sanitarios que entiendan y respeten sus valores culturales y creencias y que les ayuden de una manera significativa y apropiada. Así, el propósito de la ETC es continuar descubriendo nuevas y beneficiosas formas de ayudar a las personas de diferentes culturas o subculturas marginales, siendo el objetivo de la ETC proporcionar cuidados culturalmente apropiados. La enfermería transcultural es, en palabras de Madeleine Leininger (1999), su fundadora: un "área formal de estudio y trabajo centrado en el cuidado y basado en la cultura, creencias de la salud o enfermedad, valores y prácticas de las personas, para ayudarlas a mantener o recuperar su salud, hacer frente a sus discapacidades o a su muerte".

\section{SANACIÓN Y CURANDERISMO HOY}

Algunas personas parecen estar dotadas de una capacidad psico-biofísica que los convierte en "almas sensibles" (Amezcúa, 2004). Se trata de hombres y mujeres que poseen el don de detectar las emanaciones energéticas de su entorno y diagnosticar ciertas dolencias e incluso tienen la capacidad de curar mediante la imposición de manos y el trabajo con el magnetismo de la persona como principales fuerzas y fuentes terapéuticas.

El curanderismo es sin duda un fenómeno sociocultural tan antiguo como la propia historia del hombre, según han afirmado varios expertos en la materia (Amezcua, 1990; Granero, 1998; Salvatores, 1999). Los curanderos existen a pesar del desarrollo cultural y tecnológico de los pueblos.

El curandero, sea de la montaña, del medio rural o urbano, ha aprendido el manejo de los remedios vegetales que utiliza ampliamente. Sin embargo hay otros mecanismos en la curación popular cuyo efecto curativo no es atribuible a las plantas, esto es la sugestión. Curación o mejoría se deben muchas veces al efecto sugestivo producido sobre el enfermo por el curandero, al que rodean prestigio y misterio (Stokvis, 1983) siendo el ritual utilizado 16, uno de los factores más importantes para desencadenar el efecto sugestivo (imposición de manos, (De Miguel, 1980) lugar parecido a un oratorio (Amézcua, 1990 Pérez, A. 1990; Briones
1997). La persona más sugestionable que otras, presentan un porcentaje más elevado de «curaciones» o mejorías. Si el curandero está convencido de su poder, convence a los demás. Si se sugiere al enfermo que su dolor va a desaparecer, esto puede suceder. No olvidemos que la psique actúa sobre el soma o viceversa y que no hay enfermedades psíquicas puras ni enfermedades somáticas puras.

\section{EL CURANDERO}

Según Pérez, y Fernández (1990), se cree que pasan de 5.000 los curanderos en España, pero muy probablemente haya el doble y sólo en Andalucía oriental se estima unos 300 (McLane, 1989; Gómez, (1997). Se dan en la actualidad varios tipos de curanderos que atienden a formas tradicionales de ejercer el arte de curar y que perviven junto a los servicios sanitarios. Su nivel de profesionalidad varía de unos a otros, estando en relación directa con su ámbito de influencia. (Amézcua, 1990 ; Briones, 1996 ).El reclutamiento o la llegada al ejercicio del curanderismo sucede de formas variadas, las más generales son: por revelación divina, por aprendizaje, por enfermedad, vocacional, y por transmisión espiritual. En función de los procesos morbosos que atienden y de los remedios que emplean se pueden clasificar en: a) Los rezadores, que curan verrugas, culebrinas, dolores de muelas y otras enfermedades mediante oraciones o ensalmos que se acompañan de otros rituales simbólicos; b) Los sabios o sabias, que con método parecido curan padecimientos que tienen su origen en maleficios, como el mal de ojo, y se les reconoce poderes adivinatorios; c) Los que con su destreza personal arreglan problemas de huesos (anudadores) o poseen conocimientos para aprovechar las facultades terapéuticas de las plantas (naturalistas) (Espejo 1975); d) Los santos, que emplean medios y métodos parecidos pero se les reconoce el poder de la adivinación y la curación por influencia sobrenatural, además de ejercer como confesores y consejeros.

En la actualidad la gente llama de forma genérica a todos ellos curanderos, si bien los que se identifican devocionalmente con los santos sitúan a éstos en una categoría diferente debido a la presencia de: a) Religiosidad; b) Gracia: sinónimo de poder medianero entre lo sobrenatural y lo terreno, 
que se recibe por designación de aquél. A veces "la gracia” está asociada a fórmulas relacionadas con la herencia (el séptimo de los hijos varones), con la influencia de la luna, o con fechas con una significación especial (el viernes santo).

\section{CARACTERIÍSTICAS COMUNES}

- La mayoría de los curanderos carecen de estudios e incluso había un gran porcentaje de analfabetos, no todos viven del ejercicio del curanderismo, algunos tienen su trabajo como agricultores, pastores, comerciantes, etc., o bien lo llevan alternando con su cónyuge o algún familiar.

- El curandero siente, generalmente, que curar a los enfermos es una obligación y un deber moral que Dios les ha impuesto. La fuerza y el poder divino es lo que cura y no ellos personalmente, ya que son solamente instrumento en las manos de Dios. Ellos son sólo intermediarios entre Dios y el enfermo.

- Algunos van a buscar sus propias plantas curativas en determinadas fases de la luna o momentos del día. (Chessi, I. 1.996; Arteche, A.; Berdondes, JL. ) Otros "recetan" plantas para que el enfermo las compre.

\section{LOS CLIENTES Y SUS RAZONES}

No será la ciencia ni el saber del médico lo que les sugestione sino aquello de mágico que puedan ver en él, aunque el materialismo y el cientifismo actual en la mayoría de los casos le priva de ello. El curandero encuentra en este tipo de clientela, aquellos con los que puede hacer sus mejores y más espectaculares curaciones, sin importar el grado de preparación cultural o académica del enfermo.

Debemos añadir los casos en que el paciente ha creído ser, o lo ha sido efectivamente, tratado como un número, como una cosa, en la consulta del médico-gestor, que se limita a extender una receta y «quitarse de encima» un elevado número de pacientes en un tiempo mínimo, a lo que a veces se llama «medicina social» o socializada.

El enfermo, como ya hemos dicho en otras ocasiones, no busca la ciencia en el curandero, sino la esperanza, busca un depositario de sus problemas que le ayude a llevarlos, busca un guía, un apoyo

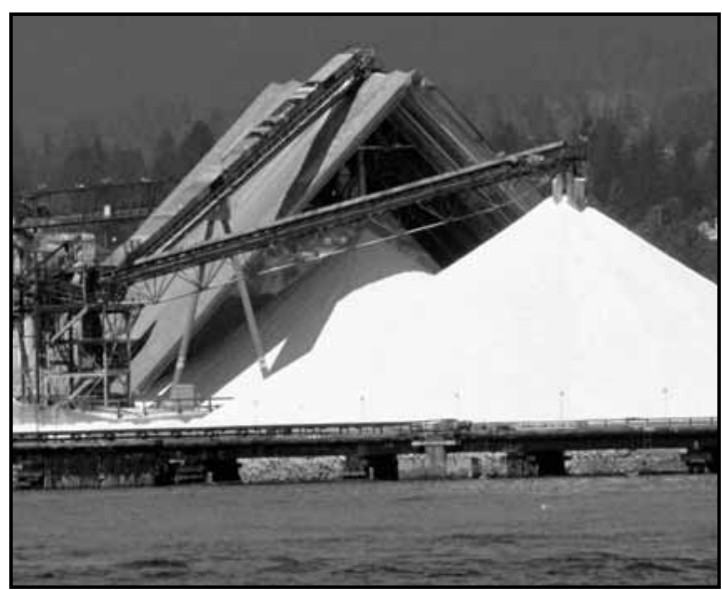

moral. Y cosa curiosa, lo encuentra muchas veces en estos hombres y mujeres iletrados, la mayoría de las veces, pero con una forma natural de conocer el alma humana. El tratamiento aplicado por el curandero actúa, en ocasiones, como un auténtico placebo, siendo lo que realmente cura la actuación sobre el factor psíquico que lleva consigo la enfermedad o el enfermo. En otras ocasiones la curación se debe al efecto intrínseco de las plantas tomadas y en otras, reconozcámoslo, no sabemos por qué sucede lo que sucede pero ahí está el resultado aunque nuestra mente lógica y racional no lo entienda, quedando por tanto abierta una puerta al esoterismo. Analizaremos este punto con más detalle con los resultados de la encuesta.

\section{EL ESTUDIO}

El relativismo cultural, opuesto al etnocentrismo, consiste en la capacidad de comprender las creencias y costumbres de otros pueblos o sociedades desde el contexto de su propia cultura, aunque estos pueblos vivan en un mismo espacio geográfico, partiendo de que todas las culturas son iguales y ninguna es superior a otra. Estos son dos conceptos que se deben tener muy en cuenta a la hora de hablar de diversidad cultural. (Harris, M. 1982) Es en el marco del relativismo cultural donde queremos centrar y justificar este trabajo. Cuando consideramos, como profesionales de enfermería, una subcultura dentro de la propia cultura del país y bajo el prisma del relativismo comprendemos sus valores, creencias y prácticas de salud junto a las de la cultura dominante, entonces la enfermera está haciendo cuidados transculturales. Como dice 
Spector, (2001) "el deseo y la demanda de los profesionales de los cuidados por convertirse en "culturalmente competentes" va en aumento"

\section{OBJETIVOS:}

1. Conocer globalmente el fenómeno de los "cuidados populares" y el curanderismo y comprender su coexistencia con modelos de salud altamente cualificados.

2. En cuanto a las personas que han asistido:

a. Conocer los motivos o razones que llevan a una persona a consultar con un curandero.

b. Cómo se han sentido.

c. Cuál ha sido el grado de satisfacción.

3. Identificar el perfil personal y los métodos utilizados por estos curanderos a través de las experiencias de los usuarios.

\section{METODOLOGÍA}

Para documentar y completar esta etnografía descriptiva se ha diseñado una encuesta administrada por el entrevistador en el momento de la entrevista con el paciente y el estudio se circunscribe a la provincia de Jaén fundamentalmente. Para la muestra se han seleccionado a 7 personas que han recibido tratamiento de curanderos en diferentes circunstancias y a los que corresponden los datos de la siguiente tabla:

\begin{tabular}{|c|c|c|c|c|}
\hline Sexo & Edad & E. Civil & Estudios & Profesión \\
\hline VARON & 47 & CASADO & SECUNDARIOS & TAXISTA \\
\hline VARON & 26 & SOLTERO & UNIVERSITARIO & INGENIERO \\
\hline MUJER & 35 & CASADA & EGB & AMA DE CASA \\
\hline MUJER & 30 & CASADA & BACHILLER & ADMINISTRATIVO \\
\hline MUJER & 60 & VIUDA & PRIMARIOS & AMA DE CASA \\
\hline MUJER & 71 & CASADA & NINGUNO & AMA DE CASA \\
\hline MUJER & 45 & CASADA & UNIVERSITARIA & ENFERMERA \\
\hline
\end{tabular}

\section{ANÁLISIS DE LOS DATOS:}

1 ¿En qué consistía su enfermedad?

- Hemorroides

- Herpes zoster (2)

- Lupus.

- Artrosis y artritis reumatoide y osteoporosis.

- "Los nervios se han metido en el estómago" (Ulcera gástrica.)

- Hepatitis C.
2. ¿Cuál es su situación frente al servicio sanitario oficial recibido?

Sólo 1 de los enfermos entrevistados no había sido visto previamente por un médico y acudieron directamente al curandero. El resto había sido visitado una o varias veces por un médico sin encontrar una mejoría aparente. Algunos han sido vistos por varios médicos.Otro ha sido operado una o varias veces. En tres casos, los enfermos reconocían que los médicos les habían tratado bien, ya fueran de la Seguridad Social o particulares, pero en el resto la frase «no me hacían caso» era la regla y por eso decidieron romper con la Medicina oficial y seguir al curandero.

3. ¿Quién le informó de la existencia del curandero?

Amigos, familiares, compañero de trabajo, otro conocía la actividad del curandero fue directamente allí.

4. Sexo y edad, presencia del curandero y del lugar de curación.

Dos de los enfermos fueron vistos por curanderas y el resto (5) por curanderos varones. El doble de curanderos fueron varones. Ninguno tiene una edad inferior a 45 años, si bien una de ellas empezó en torno a los 25 años sus actividades y otro igualmente "reconoció" su gracia y empezó a curar después de los 30 años. Sólo dos de ellos (un varón y una mujer) tenían en su domicilio abundante material religioso y encendieron velas para la sesión. Otro llevaba en la cartera varias estampas de la Virgen que sacaba y colocaba en la mesa donde está "curando", todos se santiguaron al iniciar y finalizar el tratamiento, pero en general no hubo grandes ostentaciones religiosas ni místicas.

5. ¿Por qué acudió a un curandero?

- Los tratamientos médicos no sirvieron para nada. Desesperanza.

- Miedo al tratamiento quirúrgico recomendado por los médicos y al uso de ciertos medicamentos.

- Estaban desesperados y esperaban un milagro del curandero.

- Fueron inducidos por un familiar, amigo o vecino a consultar con un curandero por curiosidad y «por si acaso». 
6. ¿De qué forma acogió el curandero su problema y cómo definió su enfermedad?

Puede observarse que en las contestaciones a esta pregunta hay un absoluto predominio de buenos recibimientos, comprensión, afabilidad, amabilidad, etc., en fin, buena acogida en la recepción del enfermo por el curandero. La bondad que emana de su persona, la atención y el buen trato en general para el enfermo, que éste sabe apreciar es una de sus más poderosas armas.

El curandero pone siempre interés en la atención del enfermo.

El curandero suele mostrar seguridad en sí mismo.

\section{7. ¿Cómo hace "su" diagnóstico?}

La mayoría utiliza las manos, bien haciendo simplemente pases sin tocar al enfermo o colocándolas quietas sobre la parte afecta. A veces toman la mano. «Me tomó la mano».

La simple observación de la parte es frecuente. La mirada fija es utilizada de diversas formas entre ellos para retener la atención del paciente.

La concentración del curandero es interpretado de diversas maneras: «meditó profundamente», «se quedó pensando», «cerró los ojos», «se concentró moviendo los labios» (como rezando).

Algunos de los entrevistados han hecho referencia a que esos mismos curanderos, en otros casos, no han necesitado ver al enfermo para diagnosticarle y bastaba llevarles una fotografía con la que curaban a distancia, concentrándose sobre la foto.

\section{8. ¿Qué tratamiento le aconsejó?}

Los tratamientos fueron muy variados: desde tomarse por vía oral varios papelillos de liar cigarros previamente bendecidos que el propio curandero da al paciente, hasta la ingesta de infusiones pasando por el uso de calor seco (una plancha eléctrica envuelta en un trapo negro) o lavarse la zona con preparados de diferentes hierbas hervidas durante periodos de tiempo diferentes según el uso, o bien frotar la zona con grasas preparadas, así como la propia imposición de manos del curandero en repetidas ocasiones. Los pacientes dicen: «sentía el calor», «sentía que pasaba calor del curandero a mí», «me preguntó si sentía calor al tocarme». Es frecuente también al iniciar y finali- zar el tratamiento santiguarse y a veces hacer cruces sobre la zona a tratar.

\section{9. ¿Ha llevado a cabo el tratamiento?}

Los enfermos en general fueron con la idea de que la fe cura. El paciente solía tener gran fe en que los medios, por más extraños que parecieran, iban a curarle. El enfermo siente necesidad de creer, sea un ama de casa o un universitario. El paciente siguió el tratamiento a veces por años. Entre los pacientes referenciados la adherencia al tratamiento del curandero ha sido excelente pero se constata que en dos casos fueron menos constantes o se aburrieron y lo dejaron. En general, como los tratamientos del curandero no suelen ser demasiado complicados el paciente no tiene el menor reparo en seguirlos.

\section{0. ¿Le cobró dinero por la visita el curandero?}

En el total de los casos referenciados en estas encuestas ninguno tuvo que pagar nada al curandero. Dos de ellos enviaron presentes en agradecimiento. Pero se conoce que otros pidan una ayuda o la "voluntad" e incluso que tengan una cuota fija establecida.

\section{1. ¿Repitió la visita al curandero?}

Todos los pacientes repitieron la visita al curandero y algunos varias visitas, o bien era el curandero el que visitaba al paciente. En ocasiones periódicamente por espacio de meses e incluso años.

La mayoría se han sentido muy aliviados de sus males con las tratamientos recibidos. Otros han hecho buena amistad con el curandero o curandera, siendo ya clientes fijos y enviándoles otros pacientes reclutados por ellos.

Todos los pacientes referenciados mostraron su voluntad de volver en un nuevo episodio de enfermedad, cuando la medicina convencional no fuera efectiva o incluso simultanearían estas visitas con los tratamientos médicos.

La frase «sí, porque tengo mucha fe en ellos» se repite con constancia machacona en las respuestas.

\section{DISCUSIÓN DE LOS RESULTADOS}

1. No encontramos diferencias con otros autores en cuanto al perfil del curandero, excepto en el hecho de su nivel académico y cultural es algo más 
elevado que la bibliografía consulta debido a que fenómenos como el analfabetismo muy presente en otros tiempo, ahora esta casi erradicado. Siguen utilizando los remedios vegetales como medio de curación y todos consideraron su actividad de sanación como una obligación derivada de un don divino y que son mediadores entre el paciente y la gracia divina.

2. En cuanto a perfil de los clientes, coincidimos con otros autores en que son mayoría mujeres y de edad entre 30 y 50 años y al igual que sucede con el perfil cultural de los curanderos, se observa una mejoría en el nivel académico de los clientes, habiendo encontrado a pesar de la corta muestra estudiada, un alto nivel de cualificación profesional.

3. No se ha podido contrastar con autores anteriores el hecho expresado por los entrevistados en cuanto a la frecuentación en veces repetidas, como en los casos estudiados. Tampoco encontramos referencias al hecho también encontrado en el que es el/la curandero/a quien se desplaza a visitar al paciente. Posiblemente porque el aislamiento en que se vivía en otras épocas se ha visto mejorado actualmente por tener fijado su domicilio el curandero en núcleos urbanos mas o menos grandes.

4. El número reducido de observaciones y la localización en un área geográfica restringida permite solamente considerar los datos en el contexto del estudio.

\section{CONCLUSIONES DE LA ENCUESTA}

- Entre los resultados de las encuestas realizadas la contestación más general fue: «El curandero me trató muy bien, con mucho afecto. Se interesó por mi problema». La solicitud, el interés por parte del curandero es ya de por sí una forma terapéutica

- Las mujeres acuden más a los curanderos, casi el doble que los varones.

- Las mujeres comprendidas en la década de los treinta a los cuarenta años y los hombres de la misma década fueron los que más acudieron a las consultas de los curanderos, siguiéndoles los de cuarenta a cincuenta y de veinte a treinta años.

- Los hombres casados y las mujeres casadas forman el grupo que más solicitó los servicios del curandero.
- En cuanto a las profesiones u oficios, fueron entre las mujeres la de ama de casa que parecieron más propensas a visitar a los curanderos.

- Las razones por las cuales se vieron impulsados a acudir a los curanderos fueron miedo a los tratamientos médicos o quirúrgicos, curiosidad, inducción por otras personas, pérdida de fe.

- Los inductores o reclutadores de enfermos fueron: amigos, vecinos, compañeros de trabaja, familiares del propio enfermo o el enfermo mismo.

- El pensamiento mágico, la superstición, la búsqueda del milagro fue uno de los más poderosos impulsos que llevaron a estos enfermos a ser vistos por curanderos.

- Se rodearon de un ambiente eminentemente místico-religioso: imágenes, altares, flores, bendiciones y cruces, oraciones y velas encendidas. Utilizaron la imposición de manos, la fisioterapia (masaje, tracción, calor, baños, etcétera) y el contacto personal.

- Recomendaron la fitoterapia, fisioterapia, a veces medicinas de Farmacia, oraciones, actos mágicos y sobre todo fe en ellos, que trataron de inculcar en sus enfermos.

- Sus diagnósticos fueron elementales y vagos o no diagnosticaron, conformándose a veces con el diagnóstico que el enfermo traía del médico.

- Generalmente no cobraban por la visita, pidiendo sólo la «voluntad» del enfermo, pero a veces, aunque esto no es el caso entre la muestra, estafaron al paciente bien con sumas elevadas cobradas directamente o bien cobrando altos precios por hierbas de herbolario cuyo valor intrínseco era muy escaso.

- En Andalucía el curanderismo es un fenómeno muy arraigado y con frecuencia aparece asociado a las particularidades socioeconómicas y culturales de la región.

\section{BIBLIOGRAFÍA}

- Amézcua, M. (2004)"La Ruta de los Milagros. Un viaje fascinante por el mundo del misticismo popular, un acercamiento a las formas complejas de curación tradicional". Col. Index narrativa. Granada

- Amézcua, M (1990) «Formas de curanderismo en Jaén en los siglos XVI y XVII», III Congreso de Folclore Andaluz. Almería

- Arteche, A. Medicina naturista y Fitoterapia. Natura Med. 1994-95. 37-38:5-9. 
- Berdonces, Josep Lluís. (2000).La fitoterapia. Rev. ROL Enferm. sep. 23(9):631-634.

- Briones Gómez, R. (1997) "Persistencia del curanderismo entre las ofertas terapéuticas de Occidente", en P. Gómez García (coord.). El curanderismo entre nosotros. Granada, Universidad de Granada. Granada, págs. 75-129.

- Briones, R.(1996) "Convertirse en curandero. Legitimidad e identidad social del curandero", en Creer y Curar: la medicina popular. Biblioteca de Etnología, n06. Diputación de Granada.

- Chessi, E.(1996) Hierbas que curan. Editors. Barcelona.

- De Miguel; et. al. (1980)“La antropología médica en España” Serie Biblioteca Anagrama de Antropología. Barcelona.

- Dionisio y Rivera, Jesús. (1999) La institucionalización del curanderismo. Un estudio a través de una historia de vida. Index Enferm. invierno. Año VIII(27):9-11.

- Espejo Machado, F. (1975) «La medicina popular en la comarca de Alcalá la Real (Jaén)

- Gómez García, P. (1997) El curanderismo entre nosotros. Granada, Universidad de Granada

- Granero Xiberta, Xavier. El fenómeno del curanderismo urbano. Trab Soc y Salud. 1998 mar. 29:201-213.
- Harris, Marvin. (1982)"Introducción a la antropología general". Alianza editorial. Madrid, Pág. 125. Relativismo cultural. - Leininger, M. (1999) "Cuidar a los que son de culturas diferentes requiere el conocimiento y las aptitudes de la enfermería transcultural". Revista Cultura de los cuidados, nº, 22-26 - McLane, M.F. (1989) «Curanderos en Andalucía oriental», en M. Kenny y J. M. de Miguel (coord.), La antropología médica en España. Barcelona, Anagrama: 167-181.

- Montefrío (Granada)», Boletín de la Cámara Oficial de Comercio e Industria de la Provincia de Jaén, $n^{\circ}$ 22-23: 431Pérez Henares, A y Fernández Galvín, V. "Los curanderos en España”. Tribuna de Ediciones de Medios Informativos. Madrid 1990.

- Salvatores, Paloma Etxebarria, Virginia Arrizabalaga, Natalia Berna, Begoña Guzmán, Spector, R. Valoración de la Herencia Cultural. Cultura de los Cuidados Digital 2001; 9. Disponible en<http://www.index. com/cultura/9revista/9_articulo_74-81.php.

- Stokvis, B. (1983) Técnicas relajadoras y de sugestión. Barcelona, Herder.

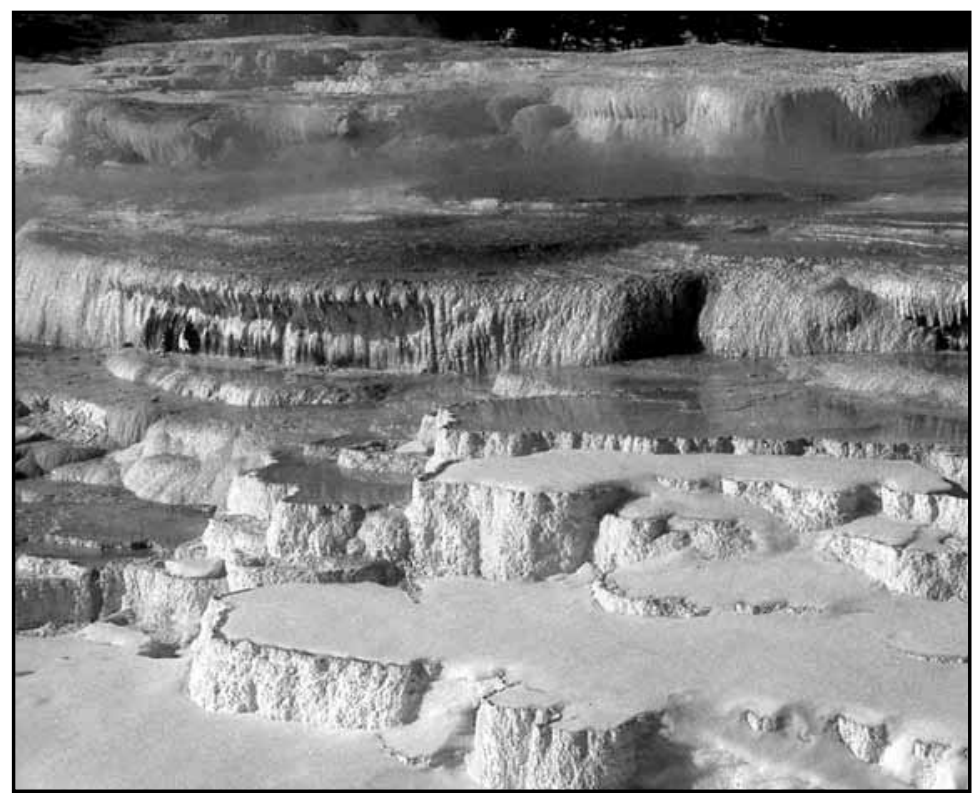

